\title{
Modelo de simbiosis para el turismo en La Macarena, Colombia. Impacto de la paz en Caño Cristales
}

\author{
Symbiosis model for tourism in La Macarena, Colombia. Impact of peace on Caño \\ Cristales
}

\section{Modelo de simbiose para o turismo em La Macarena, Colômbia. Impacto da paz em Caño Cristales}

\author{
Luz Alexandra Montoya-Restrepo ${ }^{a^{*}}$ | Iván Alonso Montoya-Restrepo ${ }^{\mathrm{b}}$ | Sandra Rojas-Berrío \\ ${ }^{a}$ https://orcid.org/0000-0002-4896-1615 \\ ${ }^{b}$ https://orcid.org/0000-0003-0959-3466 \\ c https://orcid.org/0000-0002-I I48-3779 \\ Universidad Nacional de Colombia, Medellín, Colombia
}

- Fecha de recepción: 2020-0I-16

- Fecha concepto de evaluación: 2020-04-29

- Fecha de aprobación: 2020-05-08 https://doi.org/I0.22335/rlct.vI2i2.II 32

\begin{abstract}
Para citar este artículo / To reference this article / Para citar este artigo: MontoyaRestrepo, L.A., Montoya-Restrepo, I.A., \& Rojas-Berrío, S. (2020). Modelo de simbiosis para el turismo en La Macarena, Colombia. Impacto de la paz en Caño Cristales. Revista Logos Ciencia \& Tecnología, I2(2), I I3-| 30. https://doi.org/|0.22335/rlct.v| 2i2. I I 32
\end{abstract}

\section{RESUMEN}

En este documento se presenta un modelo simbiótico turístico para Caño Cristales, ubicado en el municipio de La Macarena, Colombia, llamado como el río más lindo del mundo. Se analizan las características del modelo turístico desarrollado como estrategia exitosa del proceso de implementación de los acuerdos de paz. Como metodología, se utiliza la aplicación de la metáfora biológica organizacional para entender los procesos de cooperación en la cadena turística. El modelo simbiótico posibilita los procesos coevolutivos innovadores en la región. En esta propuesta, el desarrollo sostenible es el fundamento principal de desarrollo social, económico y ambiental. Como conclusiones, se encuentra que las estrategias de construcción de tejido social, transformación y desarrollo en entornos de paz y desarrollo sostenible, posibilitan el éxito del modelo tanto en el aspecto turístico como de proceso de consolidación de paz y cultura ciudadana.

Palabras clave: industria turística, ecoturismo, cooperación regional, desarrollo comunitario, paz 


\begin{abstract}
This document presents a symbiotic tourist model for Caño Cristales which is located in the municipality of La Macarena, Colombia, and known as the most beautiful river in the world. The characteristics of the tourism model developed is analysed as a successful strategy of the implementation of the peace agreements. As a methodology, the application of the biological organizational metaphor is used to understand the cooperation processes in the tourist chain. The symbiotic model allows for innovative coevolutionary processes in the region. In this proposal, sustainable development is the main foundation of social, economic and environmental development. It is concluded that the strategies which permit the construction of social fabric, transformation and development in environments of peace and sustainable development make the success of the model possible, both in terms of tourism as well as in the process of consolidation of peace and citizen culture.
\end{abstract}

Keywords: tourism industry, ecotourism, regional cooperation, community development, peace

\title{
RESUMO
}

Este documento apresenta um modelo turístico simbiótico para Caño Cristales, localizado no município de La Macarena, na Colômbia, chamado o rio mais bonito do mundo. São analisadas as características do modelo de turismo desenvolvido como uma estratégia bem-sucedida do processo de implementação dos acordos de paz. Como metodologia, a aplicação da metáfora biológica organizacional é utilizada para entender os processos de cooperação na cadeia turística. $O$ modelo simbiótico permite processos co-evolutivos e inovadores na região. Nesta proposta, o desenvolvimento sustentável é o fundamento principal de desenvolvimento social, econômico e ambiental. Concluindo, constata-se que as estratégias de construção do tecido social, transformação e desenvolvimento em ambientes de paz e desenvolvimento sustentável, possibilitam o sucesso do modelo tanto no aspecto turístico quanto no processo de consolidação da paz e da cultura cidadã.

Palavras-chave: indústria do turismo, ecoturismo, cooperação regional, desenvolvimento comunitário, paz

En el municipio colombiano de La Macarena, departamento del Meta, se encuentra el lugar geográfico y sitio turístico denominado "Caño Cristales". Este sitio es de destacada belleza natural, ecológica, productiva y cultural, ya que es el encuentro entre los ecosistemas andino, amazónico y orinocense; por lo cual, esta sierra goza de una gran diversidad biológica y paisajes hermosos con ríos abundantes en donde la llanura y la selva se mezclan (Marín, 2017, 2018).

La región, por muchos años, estuvo en el centro del conflicto armado colombiano. Desde los primeros inicios de los acercamientos de paz en el periodo presidencial de Andrés Pastrana, formó parte del área desmilitarizada de más de 42.000 kilómetros cuadrados, que entre 1999 y 2002, era la guerrilla la única que tenía acceso a esa maravilla natural, hasta el punto de que a Caño Cristales le llamaban "el balneario de las Farc" (Agencia EFE, 2017).

Posteriormente, con la firma del proceso de la paz con las Fuerzas Armadas Revolucionarias de Colombia (FARC), Caño Cristales surge como un atractivo de primera categoría en la variada oferta turística de Colombia, denominado como "el río más bonito del mundo", por las características únicas y endémicas del lugar, en donde Colombia promueve procesos de paz (Agencia EFE, 2017).

En el Plan Nacional de Desarrollo, 2014-2018, “Todos por un nuevo país", se propuso una sociedad en paz, educada y equitativa para desarrollar el sector turístico:"... en concordancia con la visión de país, (el cual) ha demostrado ser un importante factor de desarrollo que genera territorios de paz" (Ministerio de Comercio, Industria y Turismo, 2014) y dentro de este entorno, surge posteriormente, el programa "Turismo y paz", en donde se presentaron cuatro experiencias piloto seleccionadas: la serranía de la Macarena en el Meta, el Camino Teyuna en la Sierra Nevada de Santa Marta, el Valle de Sibundoy y Mocoa en Putumayo, y el Urabá Darién entre Antioquia y Chocó. (Bonilla, 2020; Ministerio de Industria y Turismo, 20I8).

Esta nueva posibilidad permitió encontrar en el fin del conflicto armado el factor más relevante para que el turismo en Colombia generara un crecimiento económico 
en la región: "Hace ocho años, cuando apenas recibíamos 2,6 millones de visitantes extranjeros, no imaginábamos que para 2017, un año después de finalizar una guerra de medio siglo, esa cifra llegaría a 6,5 millones" (PARES [Fundación Paz y Reconciliación], 2018, p. I).

Caño Cristales, como piloto, puede convertirse en un modelo que puede llegar a replicarse, teniendo en cuenta que se fortalece a partir de las economías locales, y con recursos propios de las familias, propone algunos de los elementos estratégicos que confluyen para el éxito del sistema turístico en el lugar. Pero, sin duda, uno de los más importantes, es la organización de la población en torno a la actividad turística como centro de desarrollo local, que no solo beneficia de forma directa a las familias vinculadas al proceso, sino que también puede fomentar el desarrollo de otros procesos productivos sostenibles en iniciativas con valor agregado, así como el cuidado del ecosistema y el fortalecimiento de las prácticas culturales propias de la región. A través del desarrollo del turismo de naturaleza y ecoturismo, se posibilitan estrategias de conservación para las áreas protegidas y la oportunidad de mantener o restaurar los valores naturales y culturales asociados a estos atractivos, a la vez que se promueve la sensibilización del visitante, se dinamiza la economía en su área de amortiguación y evita o minimiza la generación de externalidades negativas que se puedan producir por la propia actividad turística:

Al hacer partícipe a la población local de los procesos de manejo de las áreas protegidas, particularmente en los procesos de ecoturismo, es factible disminuir las presiones antrópicas que comprometen el estado de conservación de los ecosistemas. Así todos los actores interinstitucionales y de la cadena de valor del municipio de la [La] Macarena, reconocen que las bondades que han recibido por estar ubicados en un área con tanta riqueza del país, los convierte en defensores y precursores de nuevas formas de aprovechamiento del territorio (Cormacarena \& Parques Nacionales Naturales de Colombia, 2016, p. I).

El presente documento busca presentar esta iniciativa desde el punto de observación del modelo de cooperación comunitario, que puede extrapolarse mediante la metáfora biológica organizacional (Montoya, Montoya \& Rojas, 2018, 2019), como un modelo de mutualismo tipo simbiótico con procesos coevolutivos, lo cual refleja el importante éxito económico, social y ambiental que este piloto seleccionado ha demostrado en los últimos años.
Modelos de cooperación en turismo: la posibilidad de la metáfora de la simbiosis

El mutualismo, en la biología, es un tipo de relación entre especies bien diferenciadas también llamado "relación interespecífica", como se observa en la figura I, en el cual los dos individuos involucrados obtienen un beneficio mutuo. Las relaciones de mutualismo son muy importantes en las dinámicas ecológicas, en especial porque favorecen el incremento de la biodiversidad y permiten el aprovechamiento máximo de los recursos naturales disponibles, así como propician caminos que toma la evolución.

Estas interacciones biológicas se diferencian si son de individuos de la misma especie o no. Aquellos que son de la misma especie (intraespecíficas) pueden ser de ayuda y cooperación o de competencia, ya sea por recursos, crecimiento o dominación. Cuando los agentes de la cadena son de la misma categoría, pueden surgir procesos de cooperación en la competencia, esto se ha denominado la "coopetencia" (Gómez-Díaz, García-Garnica \& Curiel-Avilés, 2019).

En cuanto a las relaciones de diferentes, es decir, de los miembros de la cadena turística, que no son competencia directa, pero se necesitan, se encuentran las relaciones simbióticas. Estas pueden ser de tres tipos: el mutualismo (ganancia para todos), comensalismo (uno gana sin afectar a otro) o el parasitismo (en donde una de las especies se encuentra en desventaja por el aprovechamiento de la otra). Estas relaciones se dan de acuerdo con:

I. Relaciones recurso-recurso. En ellas, las dos especies intercambian algún tipo de sustancia o recurso biológico que es indispensable para ambas, de manera que su relación brinde una ganancia material a cada una.

2. Relaciones servicio-recurso natural. En ellas se da el intercambio de algún recurso producido, como en el caso anterior, a cambio de alguna acción o conducta que resulte beneficiosa.

3. Relaciones servicio-servicio. Es el tipo menos frecuente de relación, en la cual lo intercambiado por las especies es algún tipo de conducta o actuación, de modo tal que ambas salen beneficiadas (Del Val \& Boege, 2012).

Por su parte, la simbiosis como tipo de mutualismo, es en el que se da un grado muy estrecho de asociación entre las dos especies. Tanto así, que llevan una vida conjunta y a menudo resultan indiscernibles una de otra. Obviamente, esta cooperación presenta beneficios significativos para ambas especies, conocidas en adelante como 


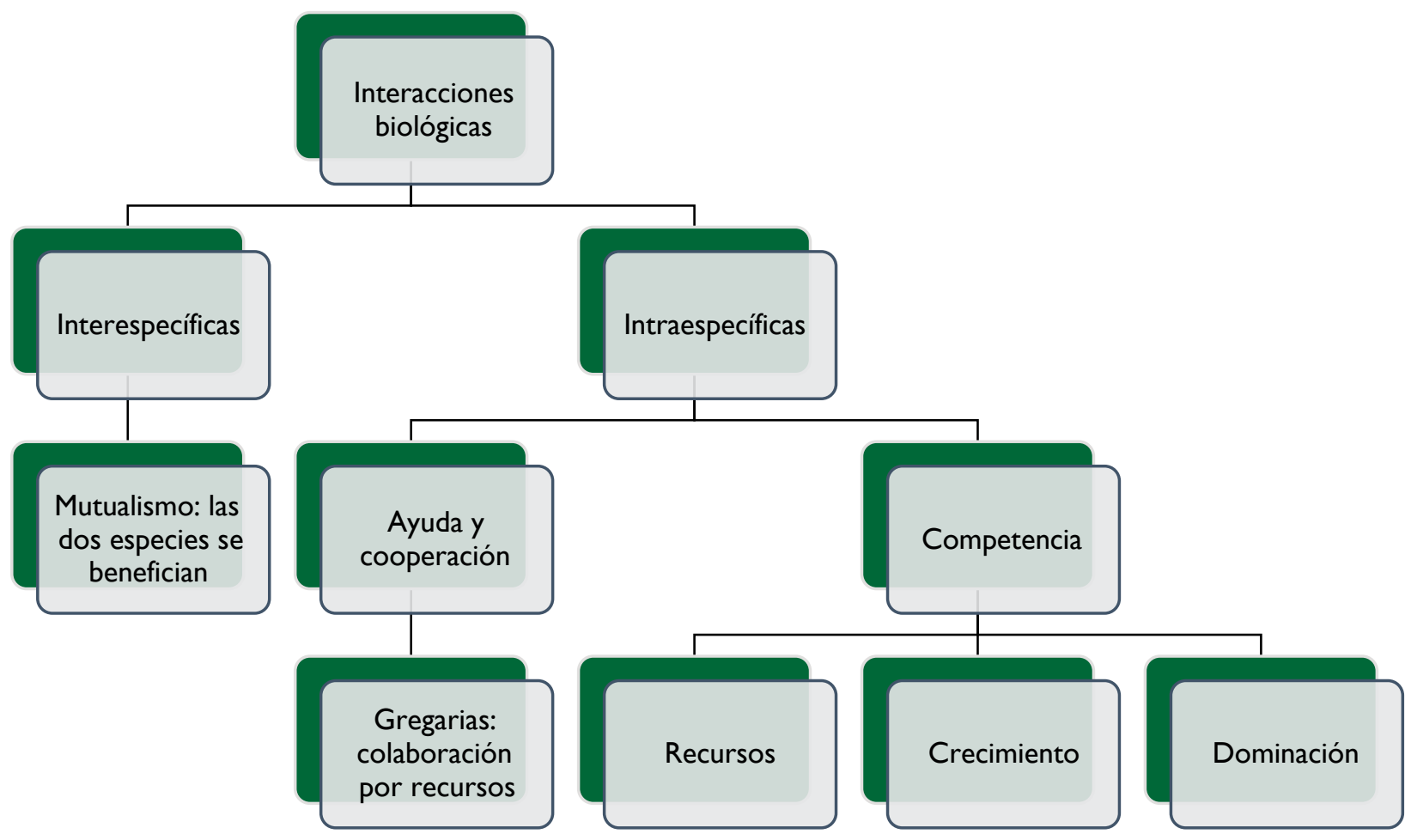

Figura I. Interacciones biológicas

Fuente: adaptada de DelVal y Boege (2012).

"simbiontes", y con el tiempo la interacción es tan fuerte que evolucionan conjuntamente, lo que se denomina "coevolución" (Hawksworth, 1989).

En los procesos de metaforización de los modelos biológicos (Montoya, Montoya \& Valencia, 2016) se encuentra cómo la comparación biológica y los procesos empresariales resultan muy útiles para el entendimiento y aplicación de elementos de colaboración interempresarial. El ecosistema, por ejemplo, en el que el modelo de simbiosis y coevolución se aplica a nivel empresarial como una comunidad de organizaciones e individuos (o grupos) que interactúan (Robinson, Baum, Golubovskaya, Solnet \& Callan, 2019). En cuanto a las relaciones simbióticas, Brun (2018) señala que no solo se limitan a la biología y la ecología: el término "simbiosis" también se utiliza para describir las relaciones económicas o financieras, $y$ ha sido empleado en trabajos de investigación que estudian colaboraciones en innovación.

Fan (2019) propuso, por ejemplo, un modelo de sistema simbiótico para las organizaciones en un sector productivo. Se fundamentó en las relaciones de interacción que denominó "energía simbiótica”, de esta manera logró precisar los beneficios económicos directos, el desarrollo de los mercados y las ventajas de la cocreación de valor. La figura 2 propone la modelización que el autor desarrolla en su modelo, en donde priman la construcción de estándares de las relaciones y los mecanismos de transferencia de distintos niveles de complejidad.

En este modelo ecosistémico en donde las organizaciones que interactúan cooperan para desarrollar modelos de negocios, tanto proveedores como competidores con el tiempo, coevolucionan en capacidades y funciones, y tienden a alinearse. Es por esto por lo que algunas organizaciones asumen roles de liderazgo que pueden cambiar con el tiempo, pero la función de líder del ecosistema es valorada por la comunidad porque permite a los miembros alinear sus objetivos estratégicos para desarrollar funciones de apoyo mutuo (Adner, 2017), lo cual debe fundamentarse en reglas claras y procesos de confianza establecidos en el tiempo (Walls \& Paquin, 2015).

\section{Metodología}

La metodología propuesta en este documento se fundamenta en una estrategia constructivista a partir del análisis de la realidad (López-Roldán \& Fachelli, 2015; 


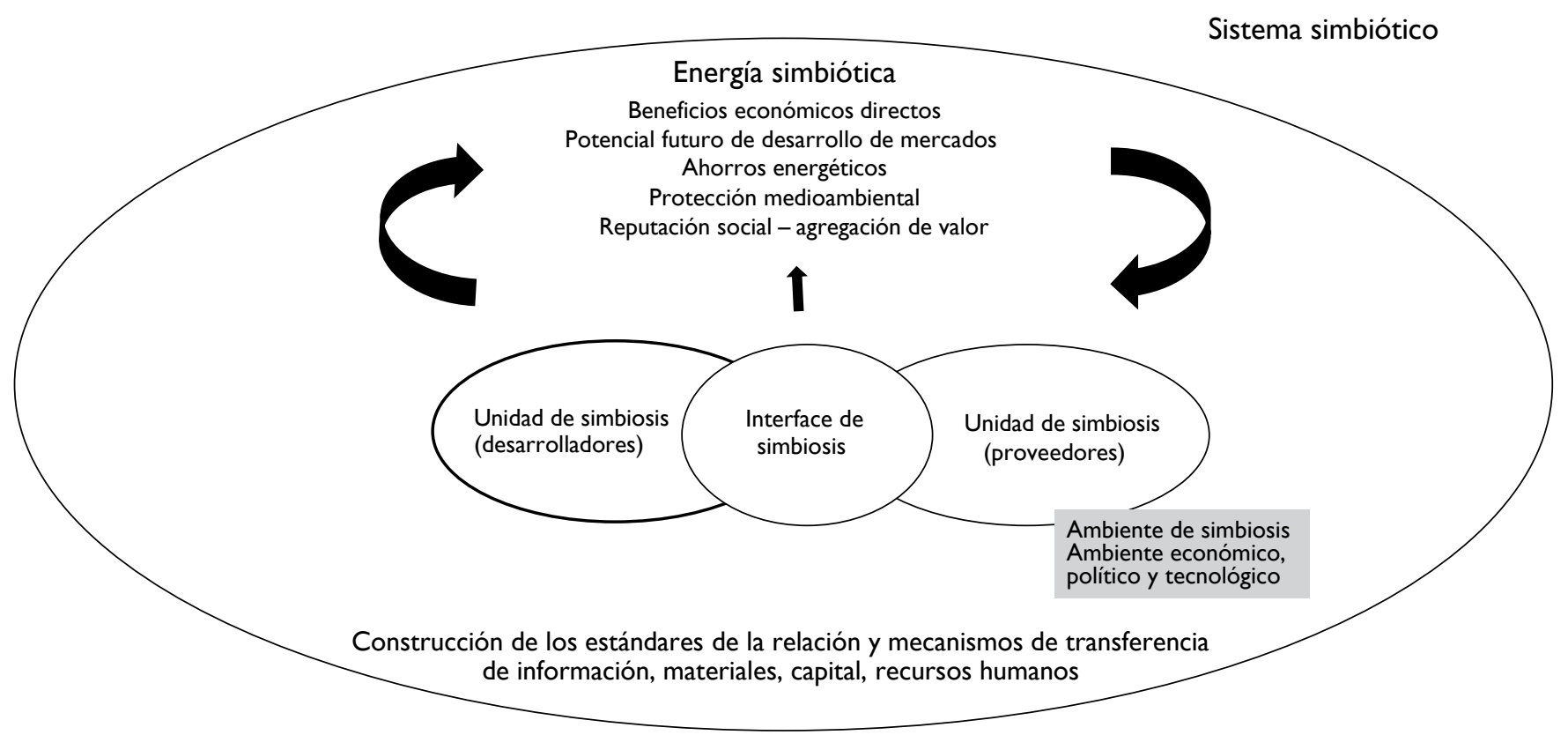

Figura 2. Modelización de un sistema simbiótico

Fuente: adaptada de Fan (2019).

Sánchez-Gómez, Rodríguez \& Costa, 2018). La cual puede observarse en la figura 3 , en donde los autores proponen, desde la teoría y la realidad empírica, una articulación y tipificación de la realidad social, con la posibilidad, incluso, de ser intervenida. Se señala que desde la realidad empírica se realiza una inducción y abstracción. En el presente trabajo se analiza la teoría para encontrar la relación con los hallazgos en campo, los cuales se tomaron gracias a las entrevistas con la comunidad (más de diez habitantes integrados en la cadena de valor del turismo en la región), en octubre de 2019, en La Macarena.

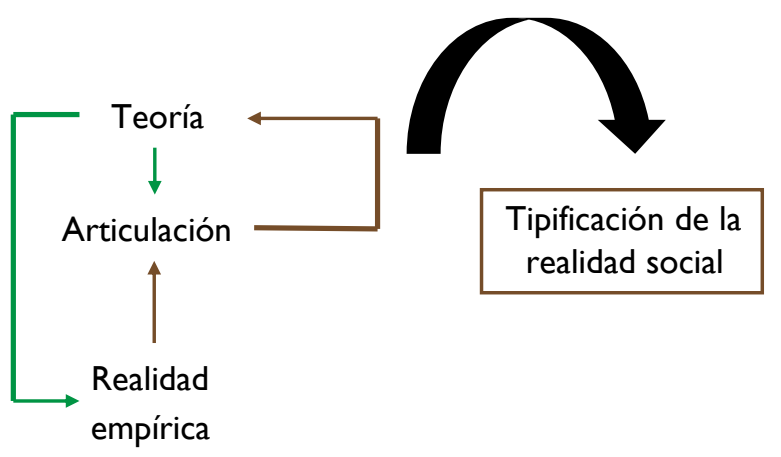

\section{Deducción/concreción Inducción/Abstracción}

Figura 3. Tipología articulada de realidad social Fuente: López-Roldán y Fachelli (2015).

\section{El turismo en La Macarena: turismo de naturaleza}

Todo proceso de desarrollo del turismo está acompañado de fuertes impactos económicos, socioculturales y ambientales, asociados a las implicaciones que produce el traslado de los turistas, su modo de actuar y la satisfacción de sus necesidades en los destinos receptores; en especial, porque con volúmenes mayores de turistas, más grandes son los impactos (Castro, 2003; González, 2018).

El turismo de naturaleza está relacionado directamente con el desarrollo y el turismo sostenible, y se encuentra inspirado en hábitats naturales y en su biodiversidad, donde adquieren gran relevancia los parques naturales, las reservas protegidas, el ecoturismo, el medio rural, el agroturismo, el concepto de territorio y el involucramiento de la población perteneciente al área turística con su entorno cultural (Martínez, 20I7).

Los modelos de turismo, en general, se centran en mostrarles nuevas oportunidades a las personas que en otros entornos no tienen acceso. El Ministerio de Comercio, Industria y Turismo (2013) señala, en la figura 4, las características de las nuevas formas de turismo: naturaleza, cultural, de bienestar y científico, centrando los de naturaleza en ecoturismo, de aventura y turismo rural, en el cual el territorio es un elemento destacado. 


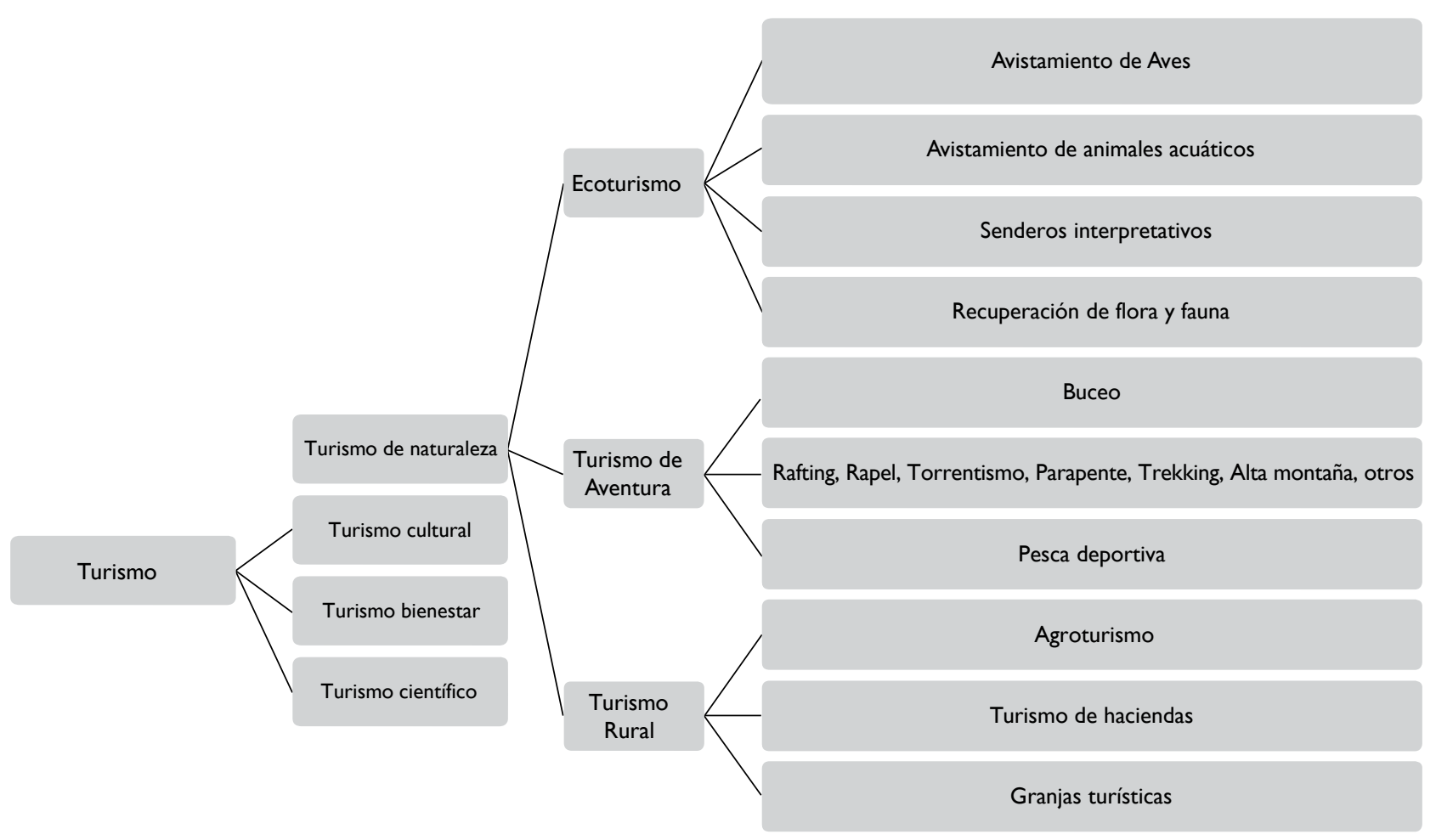

Figura 4. Caracterización de los modelos de turismo

Fuente: adaptada de Ministerio de Comercio, Industria y Turismo (2013).

Para MinComercio (20I3), la potencialidad de los productos turísticos de naturaleza se centra en los de ecoturismo y aventura, los cuales tienen un crecimiento medio y alto y desarrollo en el volumen de su mercado mundial, que puede observarse en la figura 5 .

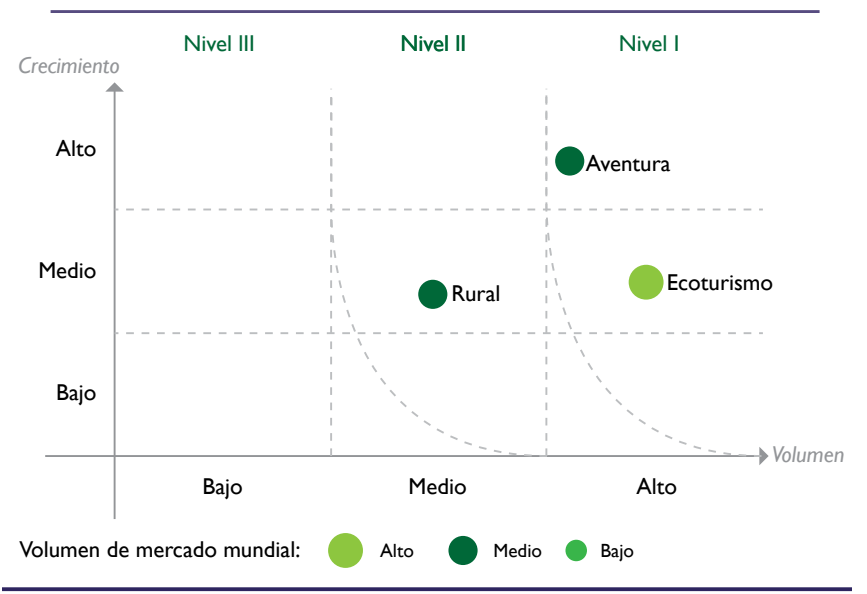

Figura 5. Potencialidad de los subproductos de turismo

Fuente: MinComercio (2013).

Una de las condiciones fundamentales es la protección del ecosistema, lo cual se dificulta cuando la carga de los turistas empieza a presionar el sistema natural; es allí en donde de nuevo se encuentra el sistema biológico y el económico. MinComercio (20l3) propone unos elementos para posibilitar la aplicación de principios de sostenibilidad, que se observan en la figura 6 .

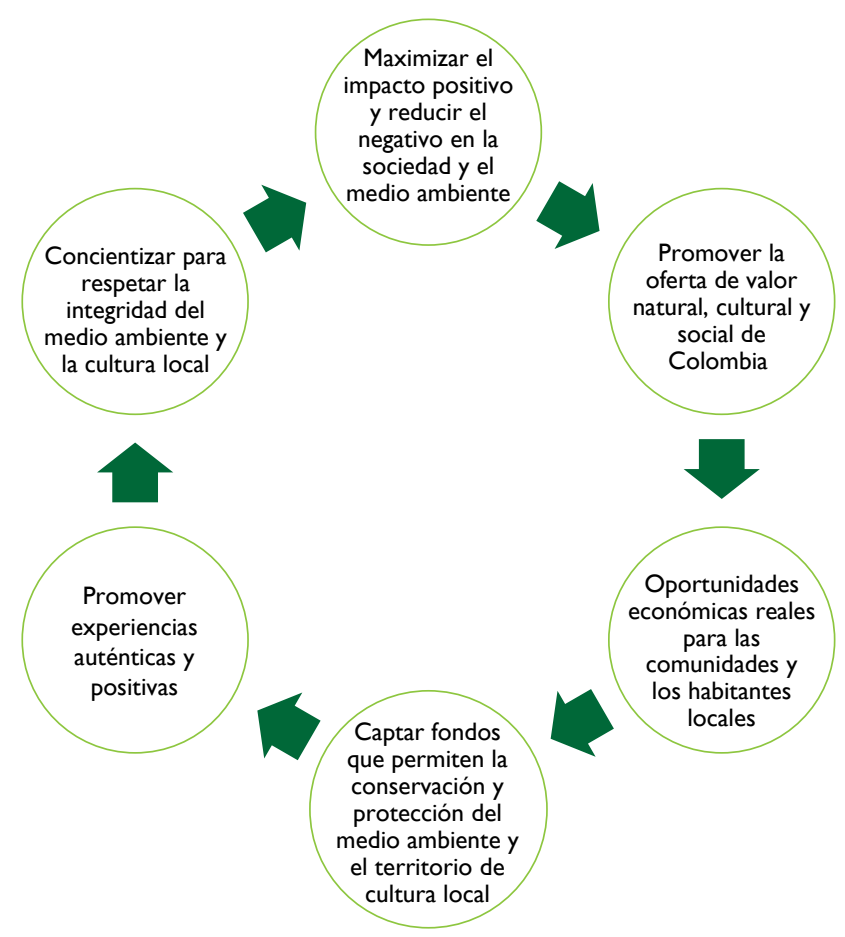

Figura 6. Aplicación de los principios de sostenibilidad de turismo de naturaleza Fuente: adaptada de MinComercio (2013). 
Uno de los elementos fundamentales se centra en el desarrollo sostenible turístico, el cual, según la Organización Mundial de Turismo (OMT), propone:

- Dar un uso óptimo a los recursos ambientales que son un elemento fundamental del desarrollo turístico, manteniendo los procesos ecológicos esenciales y ayudando a conservar los recursos naturales y la diversidad biológica.

- Respetar la autenticidad sociocultural de las comunidades anfitrionas, conservar sus activos culturales arquitectónicos y sus valores tradicionales, contribuyendo al entendimiento $y$ a las tolerancias interculturales.

- Asegurar unas actividades económicas viables a largo plazo, que reporten a todos los agentes unos beneficios socioeconómicos bien distribuidos, entre los que se cuenten oportunidades de empleo estable y de obtención de ingresos y servicios sociales para las comunidades anfitrionas, contribuyendo a la reducción de la pobreza.

- El desarrollo sostenible del turismo exige la participación informada de todos los agentes relevantes, así como un liderazgo político firme para lograr una colaboración amplia y establecer un consenso. El logro de un turismo sostenible es un proceso continuo y requiere un seguimiento constante de los impactos, para introducir las medidas preventivas o correctivas que resulten necesarias (Ministerio de Comercio, Industria y Turismo, 20 I2, p. 25).

Se encuentra, entonces, que en La Macarena se configuran los elementos de turismo de naturaleza, en especial con un enfoque sostenible que permita el desarrollo económico y que posibilite el cuidado de los recursos naturales.

\section{Elementos del ecosistema de turismo de naturaleza}

Se requiere una infraestructura sólida y estable de capital humano (el cual es capacitado no solo en el espacio físico, sino también en atención al cliente, cuidado del medioambiente, y conocimientos en ciencias básicas para la protección de los recursos), recursos físicos y planeación, de tal manera que el turismo de naturaleza permita un entorno competitivo, en el cual cada uno de los elementos de la cadena de valor interactúen para que se encuentre el modelo colaborativo-simbiótico. En general, los elementos de sostenimiento son la infraestructura, con servicios de ingeniería, bienes raíces y servicios financieros, el desarrollo de un capital humano, un desarrollo de mercado y el apoyo de organizaciones nacionales, regionales y de apoyo privado como agremiaciones y organizaciones sectoriales. La figura 7 señala los elementos de la cadena de valor que deben considerarse como "individuos" dentro del modelo ecosistémico y que contiene relaciones simbióticas, de tal forma que todos sean tenidos en cuenta y que encuentren interacción en cada uno de ellos.

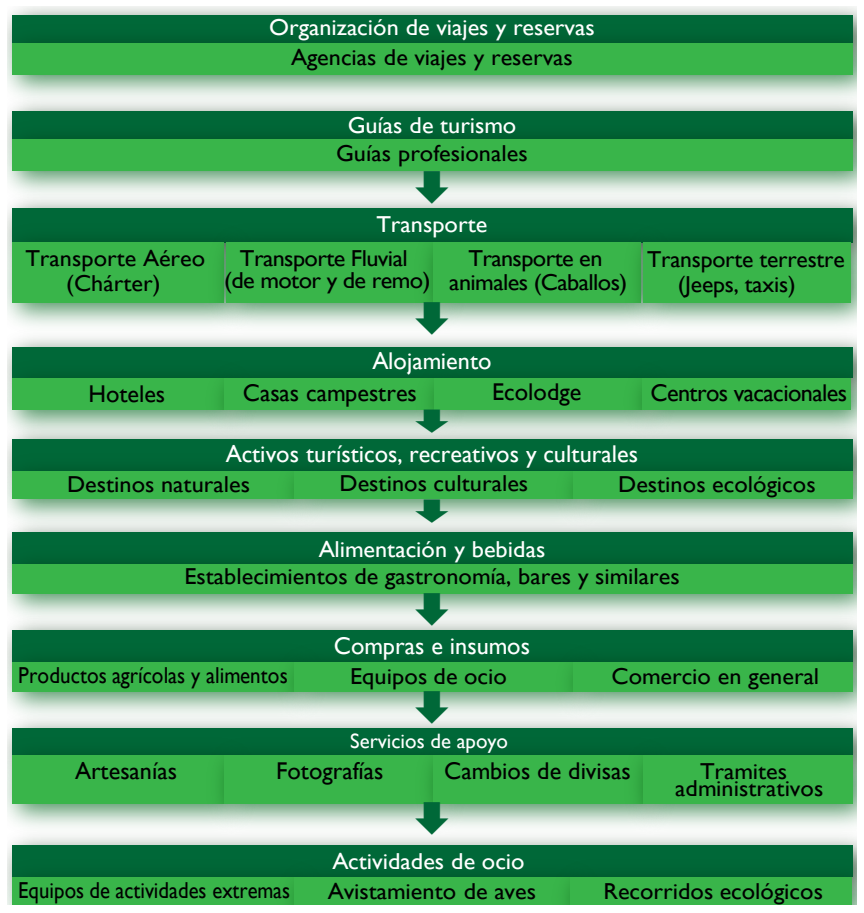

Figura 7. Elementos de la cadena de valor del turismo de naturaleza - simbiontes coevolutivos

Fuente: MinComercio (2013).

Otros elementos que deben tenerse en cuenta dentro del modelo simbiótico de turismo de naturaleza, son propuestos por Martínez (2017), y adaptados para este estudio, que se analizan en la tabla $I$.

\section{La Macarena}

La región de La Macarena cuenta con seis municipios que rodean la serranía: San Juan de Arama, La Macarena, Mesetas, Puerto Rico, Uribe y Vista Hermosa. Está conformada por la zona de influencia de los parques nacionales naturales, Sierra de la Macarena, Tinigua, Cordillera Picachos y una parte del Sumapaz. Los seis municipios forman parte, en su totalidad, del Área de Manejo Especial de La Macarena (AMEM), con una extensión de 35.875,9km2; 
Tabla I. Características de un modelo simbiótico del turismo de naturaleza

Características

Definición

Es el grado de compromiso de las organizaciones en la relación Intensidad de uso. Temporada alta (personas/ simbiótica, el nivel de confianza, la dificultad de las tareas de inte- hectáreas).

gración y los niveles organizacionales comprometidos, permiten analizar el grado de interacción. A mayor grado de interacción se encuentran mayores sinergias.

\section{Grado de interacción} Las interacciones consumen recursos y proporcionan capacidades a las organizaciones, de allí la importancia que sean no solo eficientes, sino efectivas también.

Impacto social. Proporción de turistas respecto de los residentes locales (temporada alta).

Ostrom (2013) propone el análisis de las motivaciones para la cooperación, señalando siete elementos que deben analizarse de acuerdo con su nivel de complejidad: participantes, posiciones, acciones, información, control, resultados potenciales, costos y beneficios netos (Amaya-Ventura, 2015; Ostrom, 2013).

La claridad de los objetivos por los cuales las organizaciones Protección del lugar. Medición: categoría de prorealizan la cooperación es fundamental, las motivaciones deben tección del lugar según el índice de la Unión Interser coherentes, realizables y con claridad de las expectativas. nacional para la Conservación de la Naturaleza Entre más motivaciones tengan las áreas relacionadas se tendrá (IUCN, por sus siglas en inglés). mayor posibilidad de éxito.

2. Motivación de la relación Para Olson, un asunto importante se centra en la motivación de las personas a cooperar, encontrando que cuando los grupos son pequeños y cada miembro conoce la posición del resto de miembros, se encuentran incentivos para la cooperación tipo altruismo recíproco (Olson, 200 I, 20I I, 20 I3).

Presión: número de turistas que visitan el lugar (por año y mes).

Control del desarrollo: existencia de procedimientos de revisión ambiental o controles oficiales de desarrollo del lugar y de intensidad de uso.

La duración de la simbiosis deberá estar bien definida, puede Proceso de planificación. Existencia de un plan ser en un tiempo determinado o por proyecto o por objetivo. regional organizado por la región del destino También debe indicarse si es una relación de corto plazo o por turístico.

\section{Temporalidad y permanencia de la relación}

\section{Cantidad de unidades comprometidas en la relación}

\section{Especialidad en la relación}

\section{Normatividad de la relación}

\section{Independencia de los agentes}

\section{Similitud de las organizaciones}

\section{Estructura de la cadena de valor}

\section{I.Apoyos tecnológicos}

12.Tipos de cooperación: diseño, producción, mercadeo una sola ocasión, o si se requiere un plazo medio, largo o incluso indefinido. La relación será más confiable y exitosa entre más duradera.

Cuantas unidades de negocio o departamentos se encuentran Elementos de la cadena de valor del turismo de involucrados, así como unidades geográficas o estratégicas. De naturaleza - simbiontes coevolutivos, propuestos igual forma, si son unidades funcionales o basadas en actividades en la figura 6. específicas.

La relación es inter o intrafuncional, qué unidades de la organi- Ecosistemas críticos. Número de especies poco zación se requieren y si se necesitan de apoyos complementarios. frecuentes o en peligro.

Se define si se requiere hacer institucional la relación, si las Claridad de las normas de turismo y de la prorelaciones son de carácter tácito o explícito. Se encuentra tección al ecosistema, así como de las normas regulada por normas escritas o contratos.

de desarrollo de los negocios.

Existe algún tipo de liderazgo por alguna de las organizaciones, Negocios autónomos interconectados; se enlas organizaciones son complementarias o competitivas. cuentra en el modelo, por ejemplo, la interacción de asociaciones y cooperativas, como interacción entre especies integradas por individuos.

Si son las organizaciones competencia, complementarias o Parte del éxito del modelo es la heterogeneidad pertenecen a otros sectores. El tamaño, experiencia, recursos de las organizaciones. y capacidades de las organizaciones son similares o diferentes.

Se describe si las organizaciones pertenecen al mismo sistema Incluir todos los agentes de la comunidad en de cadena de valor, como es su participación en el proceso el modelo. y de ahí sus requerimientos y necesidades.

Qué requisitos de tipo tecnológico se requieren para garantizar Desarrollos para mitigar el impacto en el la simbiosis, depende también de la ubicación geográfica y de las medioambiente, suministro de servicios públicos motivaciones de la estrategia cooperativa. básicos, infraestructura en tecnologías de la información y los pertinentes en todas las áreas que se requieran.

El nivel de cooperación y las necesidades es codiseño, copro- Satisfacción del consumidor. Grado de satisfacducción, crowfounding (recaudación de fondos) y dependiendo ción de los visitantes (basado en un cuestionario). del modelo elegido las características serán variadas. Debe Satisfacción de la población local. Grado de satisestablecerse claramente las ventajas de la simbiosis en cada nivel de la cadena de valor. facción de la población local (basado en un cuestionario). Impacto en los recursos de la región. 
Qué tan importante resulta para las organizaciones la simbiosis, Las organizaciones deben permanecer estables establecer si es posible que esta genere actividades adaptativas como sí mismas y existir mecanismos de motiy que sean recíprocas. vación para no salir de la alianza.

\section{Compromiso de la relación}

\section{Capacidad de crear ventajas conjuntas}

\section{Integración en la toma de decisiones y flexibilidad organizacional}

\section{Grado de formalización}

\section{Complementariedad / o no complementariedad de recursos}

\section{Congruencia de objetivos y valores organizacionales}

Ostrom llama particularmente su atención en la reciprocidad, la cual, en el largo plazo, trae la reputación de ser confiable. Para Ostrom, los científicos de las ciencias sociales deben cooperar más con los científicos de ciencias biológicas, como la ecología, para entender mejor los procesos de sistemas complejos adaptables (Lara, 2014; Ostrom, , 20I I; Ostrom \& Cox, 2010).

Los mecanismos de selección natural eligieron a aquellos individuos con capacidad de competir, pero también de cooperar (Ostrom, 2013).

Modificar el entorno a partir del modelo simbiótico es una El modelo coevolutivo (Montoya-Restrepo, alternativa en este tipo de organización, se debe establecer Aranda \& Montoya-Restrepo, 20II) permite claramente cuáles son los recursos y capacidades compartidos entender la capacidad de evolución conjunta de y cuáles de ellos emergen como sinergias deseables. Es ideal cada uno de los participantes de la interrelación, que todas las organizaciones adquieran las competencias que de tal forma que se encuentran ventajas de la se desarrollan de la relación, de tal forma que el mutualismo se participación dentro del sistema simbiótico. entienda como un mejoramiento para cada una de las partes.

El nivel jerárquico que toma las decisiones será fundamental Los procesos de innovación y aprendizaje en este proceso; es ideal que el compromiso sea siempre des- como colectivo permiten, en la interacción, de la alta gerencia, pero debe, a su vez, ser compartido por tomar decisiones más rápidas. todos los miembros del equipo.

Algunas organizaciones por su estructura y organización requi- Dependiendo de los requerimientos y las eren niveles de formalización de las alianzas; nuevas alternativas necesidades del ecosistema se desarrollarán organizacionales irán surgiendo a la par de la institucionalidad, alternativas del grado de formalización. entre ellas cadenas productivas, ecosistemas organizacionales, alianzas productivas o estratégicas, entre otras.

Depende del grado de similitud y de los niveles de recursos Los recursos económicos, humanos, ecológique tengan las organizaciones, se encontrarán alternativas de cos y tecnológicos deben tenerse en cuenta y complementariedad o no, dependiendo de los objetivos de la desarrollados de acuerdo con las necesidades simbiosis. de cada uno de ellos.

Los resultados de las simbiosis deben ser congruentes con los La protección del ecosistema, el desarrollo objetivos organizacionales de cada una de las organizaciones involucradas, aunque sean de nivel o impacto diferente. de la comunidad y la posibilidad evolutiva de todos los actores deben ser los principales objetivos organizacionales. La claridad de los valores posibilita el éxito del modelo.

Fuente: adaptada de Martínez (2017) y de Montoya, Montoya y Castellanos (2020).

el $90 \%$ de su área está en el departamento del Meta y el $10 \%$ en el departamento del Guaviare (Decreto 1989 de 1989), conformando, con 16 municipios del Meta y Guaviare, una región integral para el manejo ambiental (Mejía, 20l4):

\section{El Parque Nacional Natural Sierra de La Macarena está} localizado al noroccidente del departamento del Meta, y es considerado uno de los refugios de vida silvestre más significativos del planeta. Según expertos, es uno de los hitos naturales más importantes del Continente, con una flora y fauna muy particulares en las que sobresale una concentración de más de 450 especies de aves, sin comparación en el mundo. Presenta, además, yacimientos arqueológicos con petroglifos y pictogramas de las culturas indígenas que habitaron allí (Sacristán, 2007, p. I).
La planeación del gobierno Colombiano incentiva emprendimientos que se consoliden con el acuerdo de paz, por medio de propuestas concretas en los territorios que han sufrido el conflicto armado. Dos importantes programas son "Turismo, paz y convivencia" y "Seguro te va a encantar", en donde el Ministerio de Comercio, Industria y Turismo (MinCIT) pone en marcha el Plan Nacional de Desarrollo 20I4-20I8 y el Plan sectorial Turismo para la Construcción de Paz, para permitir nuevas oportunidades en las comunidades logrando beneficios económicos y sustentabilidad. (Bonilla, 20I8).

El desarrollo del turismo en La Macarena ha posibilitado la consolidación de agencias de turismo que trabajan en común acuerdo con la cadena de servicios del sector, el 
SENA que capacita todos los bachilleres, la organización de viajes y reservas, transporte, alojamiento, bebidas y comidas, artesanías y compras, activos turísticos, actividades de ocio y servicios de apoyo (PARES, 20I8). De acuerdo con los propios agentes:

"El turismo ha sido la mejor opción para nuestro pueblo. Todos nos beneficiamos", dice Henry Quevedo, llanero auténtico, nacido en estas tierras, que dirige la agencia de viajes Ecoturismo Sierra de La Macarena. Son 600 familias beneficiadas de la actividad turística, según cuentas de la Corporación Autónoma de La Macarena (Cormacarena), que custodia el lugar (Mojica, 20 I8, p. I).

Para gestionar a las organizaciones encargadas para el liderazgo de la Agenda $2 \mathrm{I}$ en la región amazónica, el Ministerio delegó al Instituto Sinchi, que ha coordinado el proceso en los seis departamentos amazónicos y en el Área de Manejo Especial de La Macarena (AMEM), junto con Corpoamazonia, la Corporación para el Desarrollo Sostenible del Norte y el Oriente Amazónico (CDA), Cormacarena, la Unidad Administrativa Especial del Sistema de Parques Naturales Nacionales (UAESPNN) y la Organización de Pueblos Indígenas de la Amazonia Colombiana (OPIAC). Sinchi es un instituto de investigación orientado a la generación y transferencia de conocimiento científico y tecnológico para la región, entiende y asume el reto que significa emprender acciones esencialmente políticas como estas; región considerada uno de los refugios de vida silvestre más significativos del planeta. Según los entendidos, se trata de uno de los hitos naturales más importantes del Continente, con una flora y fauna muy particulares en las que sobresale una concentración de más de 450 especies de aves, sin parangón en el mundo. Presenta, además, yacimientos arqueológicos con petroglifos y pictogramas de las culturas indígenas que habitaron allí (Sacristán, 2007).

Desde el punto de vista turístico, algunos de los lugares más interesantes son Caño Cristales (con presencia de una planta endémica que proporciona diferentes colores, que hace de este una maravilla visual), Caño Canoas, Caño Indio, el Salto del Águila, el Salto del Gato, Cascada del Cuarzo y la Ciudad de Piedra. También están los termales de las veredas Monserrate y Charcos, lo mismo que el salto de la quebrada La Curia. Todo esto habla por sí solo del potencial turístico del municipio para el desarrollo sostenible (Sacristán, 2007).

La organización de los diferentes actores liderada por la organización campesina Ecoamen, contribuye a construir la paz por medio de la integración de las comunidades a la economía nacional (Marín, 2018) y se apoya en el proyecto del Viceministerio de Turismo a través del proyecto "Turismo, Paz y Convivencia", el cual posibilita "preparar al sector turístico en contexto de paz, integrando a las regiones que han sido víctimas del conflicto armado a un mercado turístico incluyente que brinde opciones a las comunidades locales" (Moscarella, 20I4, p. 22), y permitiendo la transformación de escenarios de guerra a territorios de paz mediante la práctica del turismo consciente y sostenible, con el apoyo de las entidades territoriales, gremios, empresarios turísticos y la academia (Ministerio de Industria y Turismo, 2018).

En marzo de 2013, Cormacarena, Parques Nacionales $\mathrm{Na}-$ turales y el Consejo Local de Turismo del municipio de La Macarena conforman una mesa de trabajo para definir en forma conjunta la intervención y con ello ordenar el desarrollo de las actividades turísticas para Caño Cristales, cuyos componentes principales son: interpretación ambiental de los senderos ecoturísticos, reglamentación, capacitación y acompañamiento a operadores turísticos del municipio (Cormacarena \& Parques Nacionales Naturales de Colombia, 2016), lo que posibilita la estrategia "Ecoturismo por la paz", que espera generar desarrollo económico en la naturaleza, con el ecoturismo contribuye al proceso de paz como algo positivo. Genera valor para el extranjero, $y$ de orgullo e identidad en los destinos.

Las estadísticas dan cuenta del éxito de las estrategias implementadas:

Desde que se abrió el parque en 2012, Caño Cristales ha recibido 15.438 turistas según reportes de Cormacarena, la corporación que está a cargo del parque; de ellos, cerca de 10 mil[10.000] son colombianos, 3.489 extranjeros, 758 locales y 621 institucionales. De ese número de extranjeros, los países de los que más visitantes llegan son los Estados Unidos, seguidos por Francia, España, Alemania, Italia e inclusive[incluso] taiwaneses, tailandeses y coreanos, extranjeros procedentes de 77 países (Ritoré, 2019, p. I).

Además, en el 2019, La Macarena es declarada como destino turístico sostenible (Martínez, 20/9), lo cual se favorece teniendo en cuenta el desarrollo del turismo comunitario en zonas desfavorecidas:

Puede ayudar a generar recursos económicos en las poblaciones locales, contribuyendo así al desarrollo social y económico de la población y del destino. Además, esta forma de turismo puede generar una mayor concienciación de la 
comunidad local, fomentando aspectos como la conservación y respecto [sic] hacia la naturaleza y demás recursos existentes en el destino (cultura, patrimonio, etc.). El principal beneficiario del turismo comunitario es la comunidad, pues su éxito se basa en la participación local para garantizar una adecuada gestión del territorio, procurando la integración de relaciones para proteger el patrimonio turístico mientras desarrollan sus actividades de la vida cotidiana (García, Doumet \& Mendoza, 2018, p. 84).

\section{Turismo, paz y convivencia}

La estrategia del desarrollo del turismo en la región ha sido fundamental para posicionar los parques y ecosistemas, posibilitar medios económicos de subsistencia y encontrar un desarrollo sostenible con enfoque territorial, desarrollando elementos culturales y mejorando el entorno económico y social. Para ello, PARES (2018) destaca las dimensiones del proceso que pueden observarse en la tabla 2.

Además, se proponen tres estrategias fundamentales centradas en la construcción del tejido social, la transformación y desarrollo de entornos de paz y desarrollo sostenible, como se observa en la tabla 3 .

\section{Resultados de la estrategia}

El modelo de cooperación simbiótico resulta particularmente importante, porque a medida que se desarrolla el turismo se requiere que los agentes que participan en esta cadena de valor se adapten evolucionando conjuntamente. Las reglas y normas tanto legales como propias del sistema favorecen la interacción y resulta interesante la transparencia de los procesos y la baja cantidad de dificultades en el modelo, en el cual, la comunidad tiene plena claridad de la necesidad del trabajo conjunto, de los procesos coevolutivos que surgen a partir de las nuevas necesidades y de las oportunidades de la interacción simbiótica entre las diferentes organizaciones.

En especial, se destacan los mecanismos de coevolución planteados, debido a la restricción ecológica que tiene la planta endémica Macarenia clavigera, que da los siete característicos colores del caño y caños cercanos, pero que tiene su mayor esplendor desde junio a noviembre, $y$ que propone alternativas de turismo para los meses de diciembre a junio, planteando actividades que durante este periodo se centren en el turismo ecológico y sostenible y que permitan a todos mantener su entorno económico

Tabla 2. Dimensiones del proceso

Dimensión Socioeconómica: aporta a la generación de ingresos de los grupos poblacionales priorizados, junto al desarrollo económico y social del territorio de influencia, especialmente en aquellas zonas que han sido más afectadas por el conflicto y que además tienen vocación dentro del turismo, al identificar oportunidades dentro de la cadena de valor genera espacios de desarrollo económico y social.

Dimensión de Tejido Social y Cultura de Paz: apela a la reconciliación para superar las afectaciones sociales y culturales que el conflicto ha dejado en los territorios. Recurre a la memoria histórica y a la cultura de paz para superar las causas de los enfrentamientos y reducir la violencia en las conductas de las personas, especialmente de las poblaciones priorizadas, y procura mejorar la convivencia. Espacios de desarrollo económico y social.

Dimensión de Gobernanza y Fortalecimiento Institucional: busca estrechar los lazos entre el Estado y las empresas del sector en las zonas más afectadas por el conflicto, con especial énfasis en aquellas con vocación turística para así fortalecer no solo la presencia estatal, sino también la confianza que las personas pueden tener en las instituciones del Estado. Turismo de Naturaleza

Dimensión de Seguridad: busca conservar o instaurar la seguridad en los territorios. En este orden, la seguridad implica tres enfoques: I) seguridad pública que consiste en la ausencia de amenazas para el Estado; 2) seguridad ciudadana, que se refiere a la protección de derechos y libertades individuales; $y$ 3) seguridad humana, que centra su atención en la seguridad de las personas, las comunidades y las poblaciones priorizadas.

Dimensión de Responsabilidad Social y Derechos Humanos: busca que las empresas tengan un compromiso voluntario desde la alta dirección para integrar en su gestión asuntos de carácter social, medioambiental y económico. Este enfoque puede ayudar a mejorar la posición competitiva de la empresa, reducir sus costos operativos, aumentar la fidelización de los clientes y mejorar su reputación. Este aspecto es transversal y sus acciones pueden estar clasificadas dentro de las otras dimensiones señaladas 
Tabla 3. Estrategias de consolidación, turismo, paz y convivencia

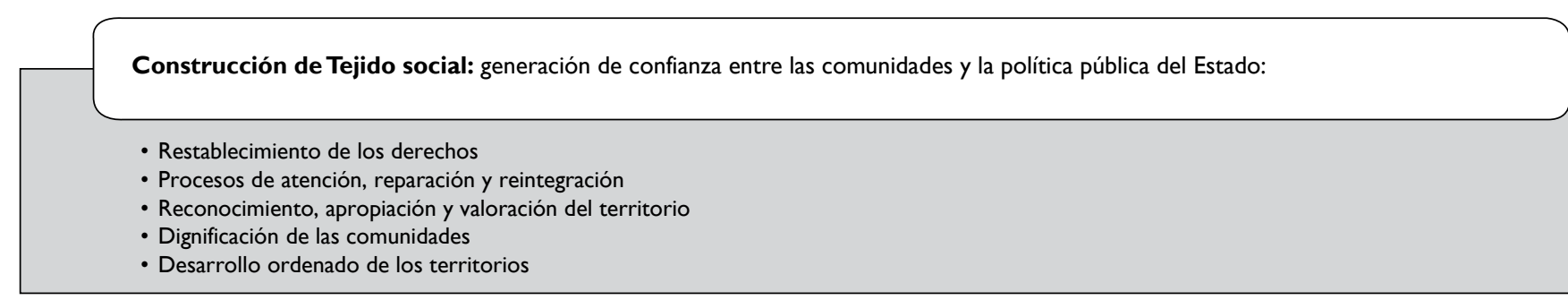

Transformación y desarrollo de entornos de paz Busca el empoderamiento de las comunidades y el arraigo al territorio a través de
oportunidades de negocios en el sector turístico. En este eje se debe avanzar en acciones orientadas a:
- Cambio de paradigmas
- Transición de estilos de vida hacia una convivencia pacifica
- Generación de asociaciones productivas

Desarrollo Sostenible: Se fundamenta en el desarrollo social, cultural, ambiental y económico de los destinos de Turismo y Paz, tomando
como base los objetivos establecidos por la Organización de las Naciones Unidas - OMT. Enfocar el desarrollo turístico de sus regiones en
el marco del desarrollo sostenible mediante las siguientes acciones:

Fuente: adaptada de MinCIT (2014).

estable. Así como el cuidado de todo el entorno natural que es vulnerable y debe protegerse.

Dentro de las estrategias establecidas por el Gobierno, que se observan en la tabla 3 , se pueden destacar las siguientes:

\section{Construcción de tejido social}

Se encuentra la integración de un importante tejido social en torno de la sostenibilidad y el turismo, con la consolidación de:

- Cuatro asociaciones de guías; de las cuales una es de guías profesionales, otra de expertos locales y dos de acompañantes. Los expertos locales son conocedores del territorio, pero sin la tarjeta profesional y los acompañantes son personas que están en proceso de formación.

- Dos asociaciones de canoas.

- Una asociación de hoteles y restaurantes.

- Dos de transporte terrestre, con los vehículos especiales para el tipo de terreno de este destino.

- Una de moto-taxistas; estos son los encargados de llevar las maletas a los hoteles.

- Una de operadores locales; los cuales se reúnen para hablar de ventas, conciliar precios para que no haya competencia desleal. Cuando un operador brinda un valor agregado en su servicio, tiene autorización de aumentar su precio en concordancia con lo acordado.

- Una asociación en la vereda La Cachivera (López, Giraldo, Posada \& Mejía, 2017).

De acuerdo con las entrevistas efectuadas en la región, se aprecia que los participantes están comprometidos en la evolución de la comunidad en general, son participativos, evitan los conflictos y tratan de encontrar la equidad y el desarrollo para todos. Buscan procesos de innovación colectiva, en la cual los procesos de coevolución son determinantes para alcanzar los objetivos propuestos y se evidencia una simbiosis de tipo mutualista, en la que los actores comparten sus activos, capacidades e intereses con un objetivo común: la satisfacción del turista.

\section{Transformación y desarrollo en entornos de paz}

La transformación se consolida en la capacidad empresarial, la orientación al consumidor y el mercado y la estructuración de servicios turísticos complejos en los cuales se trata de incluir la mayor cantidad de población posible. El fortalecimiento de una estrategia de mercadeo enfocada a diferentes tipos de consumidores con productos $y$ servicios agrupados alrededor de las expectativas, alcanza importantes niveles de satisfacción en turistas nacionales y extranjeros. 
Se destaca la importancia del Consejo Municipal de Turismo, mecanismo de regulación de la relación simbiótica, como un superorganismo que es presidido por un empresario de la zona y en el cual tienen participación los presidentes de las diferentes asociaciones con presencia en la zona. Este órgano funcional para la gestión del turismo en La Macarena colabora, en contacto directo, con la institucionalidad nacional y departamental; además, porque la información y la comunicación fluyen de forma directa entre los diferentes asociados, gracias a los lazos de amistad existentes y el respeto por el trabajo de los otros.Aquí, la coevolución permite que se tenga claro que el desarrollo de uno de los componentes de la cadena favorece el desarrollo de todo el ecosistema turístico de la región (López et al., 2017).

\section{Desarrollo sostenible}

Es un aspecto tan complejo que requiere de la multiinteracción de los organismos públicos, de orden nacional y privados para la protección del recurso natural, eje fundamental de la propuesta turística. El balance de las cargas del sistema y los turistas permiten mantener los procesos biológicos estables. La estrategia propuesta para dar el liderazgo a las autoridades ambientales para que proporcionen los permisos de ingreso de turistas a los operadores registrados mantiene un altísimo control. La Asociación de Operadores Locales creó una figura para atender a las personas que llegan de forma independiente; sin embargo:

...se pretende que todas las personas lleguen con el paquete adquirido y que los operadores externos realicen todos los contactos y negociaciones con los operadores locales. Para entrar a La Macarena, es obligatorio el seguro de asistencia y la entrada de cada turista está organizada con anterioridad para no superar la capacidad de carga (López et al., 2017, p. 27).

Las tres dimensiones resultan oportunas en el caso de estudio; ya que, si bien aún existen algunas deficiencias en infraestructura, la propuesta ha sido un trabajo conjunto, consolidado y que demuestra la colaboración simbiótica entre los participantes, permitiendo colocar al país en la lista de destinos que serán tendencia en el 2020, según la Asociación de Turoperadores de Estados Unidos (USTOA, por sus siglas en inglés). Por segundo año consecutivo, el país quedó en el top 10 del escalafón y, por primera vez, comparte el primer lugar con Egipto y Croacia (El Tiempo, 2019).

El desarrollo sostenible busca que tres importantes dimensiones como la social, la económica y la ambiental se integren para que de manera conjunta el territorio se desarrolle. Estas dimensiones pueden verse en la tabla 4 .

Tabla 4. Dimensiones del desarrollo sostenible

\begin{tabular}{|c|c|c|c|}
\hline Dimensiones & $\begin{array}{c}\text { Aspectos de } \\
\text { la sostenibilidad turística }\end{array}$ & Aspectos mínimos & Modelo simbiótico \\
\hline \multirow{7}{*}{$\begin{array}{l}\text { Dimensión } \\
\text { social }\end{array}$} & \multirow[t]{4}{*}{$\begin{array}{l}\text { Bienestar para las comunidades } \\
\text { receptoras }\end{array}$} & $\begin{array}{l}\text { - Satisfacción de los residentes locales con el } \\
\text { turismo }\end{array}$ & $\begin{array}{l}\text { Las oportunidades se distribuyen para todos } \\
\text { de forma equitativa (justicia con benevolencia). }\end{array}$ \\
\hline & & $\begin{array}{l}\text { - Efectos socioculturales del turismo en la } \\
\text { comunidad }\end{array}$ & $\begin{array}{l}\text { Se favorecen y activan los aspectos culturales } \\
\text { de la región. }\end{array}$ \\
\hline & & $\begin{array}{l}\text { - Acceso a los residentes a los principales } \\
\text { recursos turísticos }\end{array}$ & $\begin{array}{l}\text { Los habitantes tienen acceso a nuevas opor- } \\
\text { tunidades económicas. }\end{array}$ \\
\hline & & & $\begin{array}{l}\text { El bienestar de la comunidad también se encuen- } \\
\text { tra en el reconocimiento del valor ambiental de } \\
\text { la región y la posibilidad de mantenerlo y cuidar- } \\
\text { lo.Así como el desarrollo de una infraestructura } \\
\text { regional, en caminos, salud y educación, bases } \\
\text { para el bienestar de la región y fortalecer la } \\
\text { visión de emprendimiento de turismo ecológico. }\end{array}$ \\
\hline & Conservación cultural & $\begin{array}{l}\text { - Conservación del patrimonio cultural-natural } \\
\text { del destino }\end{array}$ & $\begin{array}{l}\text { Gracias al concepto de comunidad, se cuidan } \\
\text { y se protegen los patrimonios culturales de la } \\
\text { región. }\end{array}$ \\
\hline & $\begin{array}{l}\text { Participación comunitaria en el } \\
\text { turismo }\end{array}$ & $\begin{array}{l}\text { - Toma de conciencia y participación de la } \\
\text { comunidad }\end{array}$ & $\begin{array}{l}\text { En el modelo del caso Caño Cristales, es muy } \\
\text { interesante la posibilidad de darle a diferentes } \\
\text { familias, la oportunidad de integrarse. }\end{array}$ \\
\hline & Salud y seguridad & $\begin{array}{l}\text { - Aspectos sanitarios de la seguridad en el } \\
\text { destino } \\
\text { - Seguridad público-local influencia de la } \\
\text { población visitante }\end{array}$ & $\begin{array}{l}\text { La comunidad trabaja conjuntamente por la } \\
\text { seguridad y salud de ellos mismos y sus turistas. }\end{array}$ \\
\hline
\end{tabular}


Tabla 4. Dimensiones del desarrollo sostenible

Aspectos de

Aspectos de
Dimensiones $\quad$ la sostenibilidad turistica

Protección de recursos naturales - Protección de ecosistemas en peligro de valor

$$
\text { - Calidad de agua }
$$

Gestión de recursos naturales - Gestión energética escasos

- Disponibilidad y gestión del agua

Dimensión ambiental

Limitación dbiental del turismo

- Tratamiento de las aguas residuales

- Contaminación atmosférica

- Gestión del impacto paisajístico de las infraestructuras e instalaciones turísticas

Gestión ambiental

- Políticas y prácticas de gestión ambiental en los recursos turísticos

Aprovechamiento de los benefi- - Estacionalidad propia del turismo cios económicos que reporta el Empleo turístico turismo

- Beneficios económicos para las comunidades locales del destino

- Competitividad del negocio turístico

Control de las actividades turísticas - Control de la intensidad del turismo

Ordenación y control del lugar - Turismo en la planificación regional y local de destino

- Control del desarrollo

- Transporte relacionado con la movilidad turística

Diseño y gama de productos y - Creación de circuitos y redes turísticas servicios

- Oferta en actividades variadas

Dimensión económica - Actividades de marketing centradas en turismo
sostenible

- Protección de la imagen/marca destino

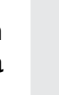




\section{Conclusión}

En síntesis, en este documento se señala cómo la implementación territorial de los acuerdos de paz y la prevención de las violencias en el posconflicto (Tabarquino, 20/8), deben fortalecer los tejidos comunitarios, que mediante la estrategia de turismo simbiótico como metáfora biológica aplicada, resulta interesante para entender los procesos de cooperación y confianza comunitarios, en los cuales, el trabajo mancomunado se fortalece a través de procesos altamente coevolutivos, en donde las innovaciones en una de las áreas promueven innovaciones en otras.

Esta estrategia permite, con el apoyo de la comunidad y el criterio de territorio como un área ambiental, geográfica, social y cultural, construir instancias de perdón, mediante la participación y el reconocimiento de todos los actores implicados en la violencia (Marín, 20I7).

La asociatividad en los territorios fortalece las relaciones con el Estado, el ordenamiento territorial (instrumento de política pública), el reconocimiento de la vocación de los territorios y las regiones (recursos y capacidades) y el desarrollo de apuestas estratégicas sólidas de mayor envergadura (inclusión social), además de la protección del territorio y sus recursos (Marín, 2017).

De acuerdo con la aplicación de la metáfora biológica para las organizaciones, se propone la utilización del concepto de "simbiosis coevolutiva" para entender los procesos, ya actuales de asociatividad y cooperación entre los diferentes eslabones de la cadena del turismo de naturaleza, fortaleciendo procesos de sostenibilidad social, económica y ambiental. La figura 8 relaciona los principales elementos de la cadena en un entorno ecosistémico, en el cual las relaciones intraespecíficas (es decir, competidores directos de la cadena) e interespecíficas (los otros eslabones de la cadena) están perfectamente coordinados para alcanzar los objetivos propuestos que además de ser de desarrollo económico y social favorecen los procesos de paz.

El desarrollo sostenible requiere coopetición (Manzhynski \& Figge, 2019), pero para que funcione, deben existir mecanismos sólidos de confianza, además de una estructura muy clara de reglas, normas y sanciones para aquellos que no la cumplen ayudan a mantener la estructura cooperativa, en general; así como en la naturaleza, se demuestra que es más eficiente estar dentro del entorno competitivo que estar por fuera como castigo por no haber entendido el proceso. Otra de las características que se emula con la naturaleza, es que tanto más personas entren en el modelo simbiótico más personas querrán estar en él, por las ventajas intrínsecas que tiene; $y$, por otro lado, es posible heredar los puestos de antecesores que fueron competitivos y que permiten seguir con negocios familiares sostenibles en el tiempo. En este sistema, aquellos individuos que se salen de los acuerdos son penalizados moralmente por los otros miembros, dando la oportunidad de evitar los agentes que no desean cooperar.

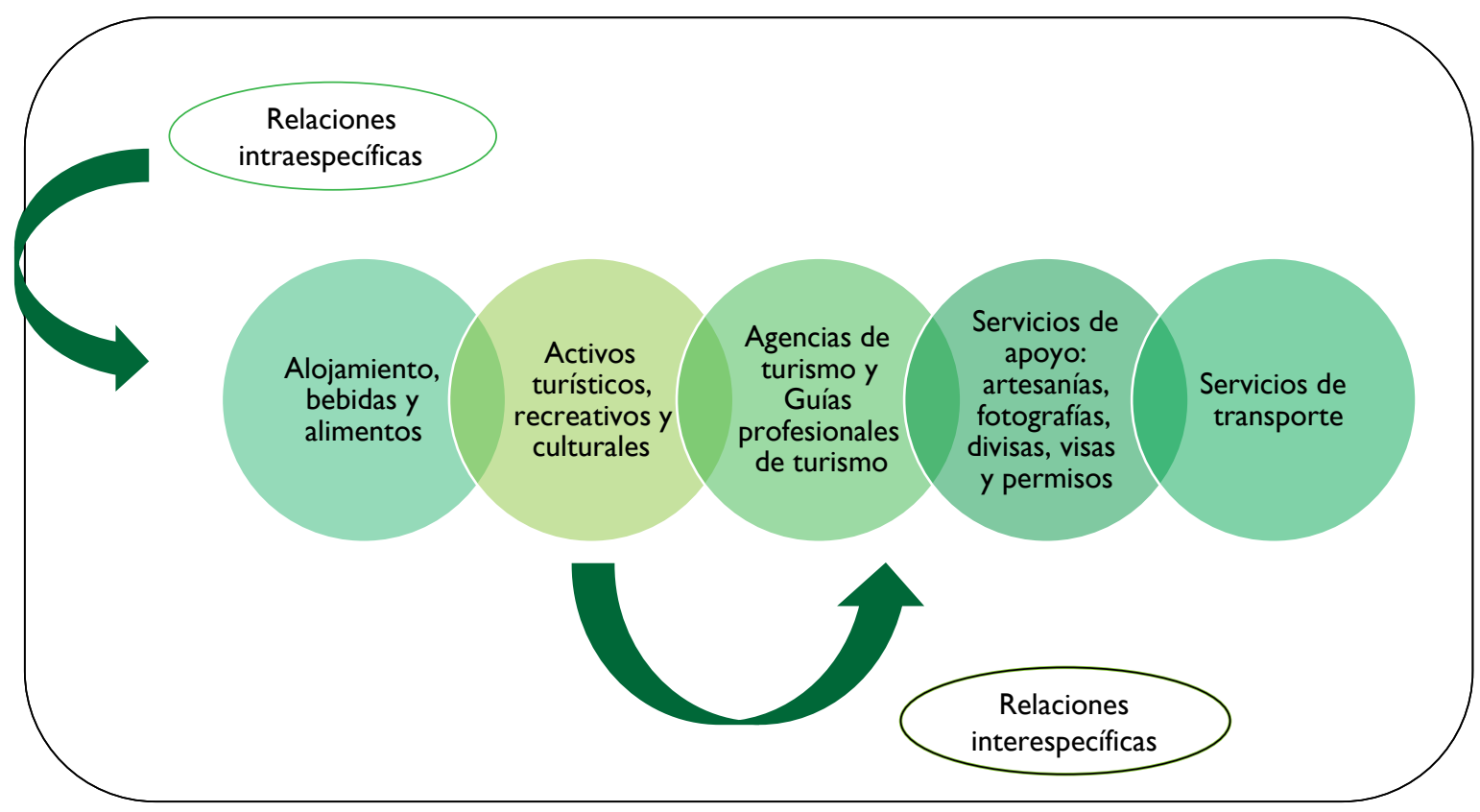

Figura 8. Eslabones primordiales de la cadena turística 


\section{Referencias}

Adner, R. (2017). Ecosystem as structure:An actionable construct for strategy. Journal of Management, 43(I), 39-58.

Agencia EFE. (2017). Caño Cristales, "el río más bonito del mundo" que Colombia redescubre con la paz". Septiembre 28, 2017 - II:14 a.m. En https://www.elpais.com.co/ medio-ambiente/cano-cristales-el-rio-mas-bonito-delmundo-que-colombia-redescubre-con-la-paz.html.

Alcaldía Municipal de La Macarena. (2013). Plan Integral de Seguridad y Convivencia Ciudadana, 2013-2015. "Seguridad y Convivencia en Buenas Manos”. La Macarena.

Amaya-Ventura, M. de L. (20I5). Elinor Ostrom. Comprender la diversidad institucional. Argumentos, 28(77), 237-243.

Bonilla, J. (2020). Turismo, paz y posconflicto. En https://zero.uexternado.edu.co/turismo-paz-y-posconflicto-en-colombia/

Brun, J. (20/8). Symbiotic innovation: Towards organizational structures relying on knowledge interdependency to foster the innovation process. Earlybird - Baltimore, United States. EURAM 2018 (European Academy of Management) Conference.

Castro, H.A. (2003). Contradicciones entre turismo, economía y ecología. Revista Economía y Desarrollo, 134(2).

Cormacarena \& Parques Nacionales Naturales de Colombia. (2016). A, B, C para visitar Caño Cristales y otros atractivos turísticos del AMEM. En http://lamacarenameta.micolombiadigital.gov.co/sites/lamacarenameta/content/ files/000003/I06_abccaocristales.pdf.

Del Val, E., \& Boege, K. (20I2). Ecología y evolución de las interacciones bióticas. Fondo de Cultura Económica.

El Tiempo. (2019). Colombia será la tendencia en 2020: empresarios de turismo de EE. UU. Disponible en https://www. eltiempo.com/vida/viajar/colombia-destino-turistico-quesera-tendencia-en-2020-segun-ee-uu-440684?fbclid=IwA RInD4oCOxNOopIrOfuAhDvfN5lubF34p4ImdebvglvQgT-6Z24weffqLo.

Fan, Y. (2019). Symbiotic system and benchmarking research of prefabricated construction chain based on symbiosis theory. Politécnico de Milano. En https://www.politesi.polimi.it/handle//0589//485/2.

García, N., Doumet, C., \& Mendoza, I. (2018). Evaluación de los recursos turísticos para el desarrollo sostenible del turismo comunitario en Manabí. En M. A. Díaz, C. E. Belezaca, A. N. Moreno y M. S. Carranza. Dossier Académico: bosques, recursos naturales y turismo sostenible. Recuperado de http:// repositorio.cidecuador.org/bitstream//23456789/49/I/ Dossier\%20Academico\%20Bosques\%20Recursos\%20Naturales\%20y\%20Turismo\%20Sostenible.pdf.

Gómez-Díaz, J., García-Garnica, A., \& Curiel-Avilés, G. (2019). Coopetencia, interaction of two antagonist relations. Dimensión Empresarial, I 7(I), I30-I 37.

González, J. (2018). Turismo y cultura en el marco de un contexto de posconflicto. Caso: La Macarena-Meta. Bogotá: Universidad Externado de Colombia, Facultad de Administración de Empresas Turísticas y Hoteleras.

Hawksworth, D. L. (1989). Interacciones hongo-alga en simbiosis liquénicas y liquenoides. Anales del Jardín Botánico de Madrid, 46(I), 235-247.

Lara,A. (2014). Elinor Ostrom: elección racional y complejidad. Elinor Ostrom (2014), Comprendiendo la diversidad institucional, México: FCE-UAM.

López, L., Giraldo, C., Posada, F., \& Mejía, D. (20I7). Análisis del proceso de transición de los cinco territorios pilotos de la estrategia turismo, paz y convivencia hacia su inclusión en el mercado turístico. Medellín: Institución Universitaria Colegio Mayor de Antioquia. Recuperado de http://www.mincit.gov.co/CMSPages/GetFile.aspx?guid=8823d623-db3e440a-a568-9069c2c43648.

López-Roldán, P., \& Fachelli, S. (20I5). Metodología de construcción de tipologías para el análisis de la realidad social. Barcelona:Universitat Autónoma de Barcelona. Grup de Recerca Educació i Treball. https://ddd.uab.cat/record// I 8082.

Manzhynski, S., \& Figge, F. (2019). Coopetition for sustainability: Between organizational benefit and societal good. Business Strategy and the Environment.

Marín, K. (2017). Construcción de paz en escenarios de violencia intracomunitaria. Estudio de caso: Sierra de La Macarena (Meta-Colombia). Estudios Políticos, (5I), 196-2I7. https://dx.doi.org//0.17533/udea.espo.n5 Ial0

Marín, K. (2018). Así se ha transformado el turismo en La Macarena. Revista Semana. Sección comunidad, 7/31/2018. Disponible en https://www.semana.com/contenidos-editoriales/colombia-me-encantas-/articulo/asi-se-ha-transformado-el-turismo-en-la-macarena/577444.

Martínez, M., Serrano, A., Montoya, A., \& Montoya, I. (20I7). La metáfora biológica como metodología de aprendizaje organizacional. El caso de los ecosistemas de innovación. Revista Espacios, 38(43). En http://www.revistaespacios. com/a I7v38n43/I73843I8.html. 
Martínez-Quintana,V. (2017). El turismo de naturaleza: un producto turístico sostenible. Arbor, 193(785): a396. https:// doi.org/I0.3989/arbor.20I7.785n3002

Martínez, Y. (2019). Declaran a La Macarena (Meta) como destino turístico sostenible. RCN-Radio, 28 de agosto de 2019 - 12:46 p.m., https://www.rcnradio.com/colombia/llanos/ declaran-la-macarena-meta-como-destino-turistico-sostenible.

Mejía, J. (20I4). La Macarena. En http://www.colombiaturismoweb.com/DEPARTAMENTOS/META/MUNICIPIOS/LA\%20MACARENA/LA\%20MACARENA.htm.

Ministerio de Comercio, Industria y Turismo (MinCIT). (20/4). Turismo, paz y convivencia. Sierra de La Macarena, departamento del Meta. Recuperado de http://www.mincit.gov.co/ minturismo/analisis-sectorial-y-promocion/turismo-y-paz.

Ministerio de Comercio, Industria y Turismo (MinCIT). (N.D.). Turismo, paz y Convivencia. Recuperado de http://www. mincit.gov.co/minturismo/analisis-sectorial-y-promocion/ turismo-y-paz.

Ministerio de Comercio,Industria y Turismo.(2013).Plan de Negocio de Turismo de Naturaleza de Colombia. Recuperado de https:// www.ptp.com.co/CMSPages/GetFile.aspx?guid=2ef226c35cb5-4I0a-b08I-ad762c9f4el7.

Ministerio de Comercio, Industria y Turismo. (20I2). Política de turismo de naturaleza. Documento preliminar. Bogotá, septiembre de 2012. Recuperado de http://www.bogotaturismo.gov.co/sites/intranet.bogotaturismo.gov.co/files/ POLITICA\%20DE\%20tURISMO\%20DE\%20NATURALEZA.pdf.

Ministerio de Comercio, Industria y Turismo. (2014). El Plan Nacional de Desarrollo, 2014-2018: todos por un nuevo país. Recuperado de https://www.minagricultura.gov. co/planeacion-control-gestion/Gestin/Plan\%20de\%20 Acci\%C3\%B3n/PLAN\%20NACIONAL\%20DE\%20DESARROLLO\%2020 I 4\%20-\%2020I8\%20TODOS\%20POR\%20UN\%20 NUEVo\%20PAIS.pdf.

Ministerio de Industria y Turismo. (2018). Documento base de turismo, paz y convivencia. Recuperado de http://www.mincit.gov.co/CMSPages/GetFile.aspx?guid=a5de7 I88-9f644|87-b688-|4d2eded977f.

Mojica, J. (2018). La Macarena, más allá de Caño Cristales. Recuperado de https://www.eltiempo.com/vida/viajar/turismoen-la-macarena-ciudad-de-piedra-y-la-laguna-del-silencio-20I 240.

Montoya, A., Montoya, I., \& Castellanos, O. (2020). Gestión de mercadeo en entornos colaborativos y plataformas en la red.
El caso del marketing simbiótico. Universidad Nacional de Colombia. (En prensa).

Montoya, A., Montoya, I., \& Rojas, S. (2019). Innovación organizacional como un proceso de simbiogénesis. Revista NOVUM, Revista de Ciencias Sociales Aplicadas, (I). pp. I24-142. .

Montoya, A., Montoya, I., \& Valencia,A. (Eds.). (2016). Metáforas biológicas aplicadas a las organizaciones II. Ensayos escogidos. Bogotá: Editorial Universidad Nacional de Colombia.

Montoya, L. A., \& Montoya, I. A. (20I2). Metáforas biológicas: aplicadas a las organizaciones. Universidad Nacional de Colombia, Facultad de Ciencias Económicas, Centro de Investigaciones para el Desarrollo.

Montoya-Restrepo, L. A., Aranda, Y.V., \& Montoya-Restrepo, I. A. (20II).Aplicación de un modelo coevolutivo a la construcción de redes para el desarrollo rural territorial. $16^{\circ}$ Encuentro Nacional sobre Desarrollo Regional en México, AMECIDER 201I. México:Veracruz, octubre.

Montoya-Restrepo,A., Montoya-Restrepo, I.A., \& Rojas-Berrío, S. P. (20I8). Propuesta de un modelo ecosistémico para la cadena productiva de la coca con fines alternativos en Colombia. Revista Logos, Ciencia \& Tecnología, I0(I), 84-94. https://doi.org/I0.22335/rict.v10il.50I

Moscarella, J. (2014). Informe de gestión 20/2- 20I4. Dirección de Análisis Sectorial y Promoción. Ministerio de Comercio, Industria y Turismo - Viceministerio de Turismo. Bogotá. Recuperado de http://www.citur.gov.co/upload/ publications/documentos/I55.Plan_sectorial_de_turismo_2014_20I8.pdf.

Olson, M. (200I). Poder y prosperidad: la superación de las dictaduras comunistas y capitalistas. España: Siglo XXI Editores.

Ostrom, E., \& Cox, M. (2010). Moving beyond panaceas: a multi-tiered diagnostic approach for social-ecological analysis. Environmental conservation, 37(4), 45 I-463.

Ostrom, E. (20I I). El gobierno de los bienes comunes. La evolución de las instituciones de acción colectiva. México: UNAM / IIS ICRIM / FCE.

Ostrom, E. (20I3). Comprender la diversidad institucional. Oviedo: KRK.

PARES (Fundación Paz y Reconciliación). (20I8). Invirtiendo en el futuro. Suplemento de construcción de paz para el sector de turismo en Colombia. No. I. Fundación Paz \& Reconciliación. Bogotá. Recuperado de https://pares. com.co/wp-content/uploads/2018/04/I-Suplemento-deconstrucci\%C3\%B3n-de-paz-para-el-sector-de-turismoen-Colombia.pdf.

Ritoré, O. (2019). Caño Cristales: el milagro que produjo el único río del mundo que florece. En https://www.las2orillas.co/ 
cano-cristales-el-milagro-que-produjo-el-unico-rio-delmundo-que-florece/.

Rivera-Cabrera, Y. L., \& Echeverri-Rubio, A. (2020). Turismo y paz: una estrategia de desarrollo local sostenible en el municipio de Florencia, Caquetá. NOVUM, I(I0), 4260. https://revistas.unal.edu.co/index.php/novum/article/ view/79790.

Robinson, R. N., Baum, T., Golubovskaya, M., Solnet, D. J., \& CaIlan,V. (2019).Applying endosymbiosis theory:Tourism and its young workers. Annals of Tourism Research, 78, 102751.

Sacristán, F. (2007). Construyendo Agenda 2 I para el municipio de La Macarena: una construcción colectiva para el desarroIlo sostenible de la Amazonia colombiana. Bogotá: Instituto Amazónico de Investigaciones Científicas Sinchi. Recuperado de https://www.sinchi.org.co/files/publicaciones/ publicaciones/pdf/macarena.pdf.

Sánchez-Gómez, M. C., Rodríguez, A. I., \& Costa, A. P. (20|8). Desde los métodos cualitativos hacia los modelos mixtos: tendencia actual de investigación en ciencias sociales. RISTI-Revista Ibérica de Sistemas e Tecnologias de Informação, 28, IX-XII. https://doi.org//0.170 I3/risti.28.0
Tabarquino, R. A. (2018). La construcción de paz e interiorización del posconflicto en Colombia: tres décadas de garantía. Reflexión Política, 20(40), 50-66. https://doi. org//0.29375/01240781.34I3

Townsend, J. D. (2003). Understanding alliances: A review of international aspects in strategic marketing. Marketing Intelligence \& Planning, 2 I (3), I43-I55.

Varadarajan, P. R., \& Rajaratnam, D. ( 1986). Symbiotic marketing revisited. Journal of Marketing, 50(I), 7-I7.

Walls, J. L., \& Paquin, R. L. (20I5). Organizational perspectives of industrial symbiosis: A review and synthesis. Organization \& Environment, 28(I), 32-53. 